\title{
Profile of maternal near miss and determinant factors in a Teaching Hospital, Southwestern Nigeria
}

\author{
Olusola P. Aduloju ${ }^{1 *}$, Tolulope Aduloju², Oluwadare M. Ipinnimo ${ }^{3 *}$
}

\begin{abstract}
${ }^{1}$ Department of Obstetrics and Gynecology, College of Medicine, Ekiti State University, Ado-Ekiti, Ekiti State, Nigeria

${ }^{2}$ Department of Medical Social Services, ${ }^{3}$ Department of Obstetrics and Gynecology, Ekiti State University Teaching Hospital, Ado-Ekiti, Ekiti State, Nigeria
\end{abstract}

Received: 11 June 2018

Accepted: 03 July 2018

\section{*Correspondence:}

Dr. Olusola P. Aduloju,

E-mail: peter.aduloju@yahoo.com

Copyright: ( ) the author(s), publisher and licensee Medip Academy. This is an open-access article distributed under the terms of the Creative Commons Attribution Non-Commercial License, which permits unrestricted non-commercial use, distribution, and reproduction in any medium, provided the original work is properly cited.

\begin{abstract}
Background: Maternal near miss (MNM) concept is becoming a tool for the assessment of severe maternal morbidity. The study examined the profile of MNM cases and their determinant factors.

Methods: A cross-sectional study of pregnant women with near miss cases and maternal death using the WHO criteria between $1^{\text {st }}$ January 2015 and $31^{\text {st }}$ December 2016. Relevant data were collected with using a structured data form, analyzed using SPSS version 22 and logistic regression was done to determine factors associated with MNM.

Results: The MNM incidence ratio was $17.4 / 1000$ live births with overall mortality index of $17.5 \%$. Hemorrhage (39.4\%) was the commonest cause of MNM while uterine rupture $(42.8 \%)$ was the most common cause of maternal death. Also, uterine rupture had the highest mortality index of 33.3\%. Older age group, low education, rural dwellers and unbooked status of women were the significant determinants of MNM, $\mathrm{p}<0.05$. The overall maternal death to near miss ratio was 1:4.7. The worst perinatal outcome occurred in women who suffered maternal death.

Conclusions: The study showed suboptimal level of care for women with life threatening conditions. There is a need to develop evidence-based protocol for their management and provision of high dependency unit.
\end{abstract}

Keywords: Determinant factors, EKSUTH, Maternal near miss, Maternal death, Southwestern Nigeria

\section{INTRODUCTION}

Pregnancy and childbirth complications are major causes of maternal morbidity and mortality globally and especially in the developing countries. Women who survive these complications could serve as surrogates to help us gain a better understanding of the set of conditions and preventable factors that contribute to maternal death and this is known as maternal near miss concept.

Maternal near miss (MNM) concept is gradually becoming a tool for the assessment of severe acute maternal morbidity. ${ }^{1,2}$ The World Health Organization (WHO) defines MNM as a woman who almost dies but survives a complication during pregnancy, childbirth or within 42 days after termination of pregnancy. ${ }^{3}$

In the past, MNM was defined using different criteria. ${ }^{4}$ There were three major approaches to the identification of near miss cases: Clinical criteria related to a specific disease entity (pre-eclampsia, postpartum hemorrhage); Management-based criteria (admission to intensive care (ICU), need for a blood transfusion); or Organ system dysfunction based criteria., ${ }^{5,6}$ Depending on these different approaches, prevalence of near miss varies. The 
MNM concept has helped in overcoming these challenges and WHO has adopted this as a tool in the assessment of quality of obstetric care..$^{3,7}$

However, in 2009, the WHO working group for maternal mortality and morbidity classifications developed a consensus on maternal near-miss identification. This is based on two components: Identification of potentially life-threatening conditions, which may or may not be near-miss cases (specific complications such as severe preeclampsia and/or critical interventions such as blood transfusion) and identification of near-miss cases based on organ system dysfunction and organ-dysfunction proxies including clinical, laboratory and management criteria. ${ }^{8}$ The investigation of near miss events provides important details on factors that may contribute to both maternal death and near miss. Knowledge on the prevalence and causes of near miss may indeed constitute a new form of evaluating obstetric care. ${ }^{9}$

The prevalence of MNM varies among different countries and regions depending on the health care quality and availability. The prevalence also depends on the different approaches used with only few studies done in low income countries of the world including Nigeria. The prevalence rates of MNM ranged between 6 and 149.8/1000 live births for disease specific criteria, between 0.4 and 45.4/1000 live births for management based criteria and between 1.4 and 9.2/1000 live births for organ based dysfunction based on Mantel criteria. ${ }^{3}$ The prevalence of MNM from a study done in Sagamu, Nigeria by Oladapo et al was 173/1000 live births. ${ }^{9}$

Ekiti State University Teaching Hospital (EKSUTH), Ado-Ekiti, Nigeria was established in 2008 and there has been no known publication on MNM or maternal death enquiries till date. Therefore, this study was aimed at evaluating the quality of obstetric care in this centre by examining the profile of MNM cases and the determinant factors.

\section{METHODS}

This was a cross-sectional study of cases of all pregnant women admitted for deliveries or pregnancy related complications in the Department of Obstetrics and Gynaecology of Ekiti State University Teaching Hospital (EKSUTH), Ado-Ekiti, southwestern Nigeria between $1^{\text {st }}$ January 2015 and $31^{\text {st }}$ December, 2016. EKSUTH is a tertiary healthcare institution and it serves as a referral centre for primary and secondary healthcare facilities located in State. There are also referrals from the neighboring states of Ondo, Osun, Kwara and Kogi. The Department of Obstetrics and Gynecology has eight consultants divided equally into two firms. The Department runs Antenatal and Postnatal Clinics on Wednesdays and Fridays and a Booking Clinic on Tuesdays. About 150 women register for antenatal care monthly in this centre with a monthly delivery rate of
130-155 deliveries, out of which about 30-35 are unbooked.

The hospital provides a $24 \mathrm{hr}$ services for obstetric and gynecological care. The hospital has a functioning blood transfusion service that provides blood from its limited stock. This is complemented with the ones that are sourced from the National Blood Transfusion Centre located not too far from the hospital and donated by patients' relatives. The hospital also has a two bedded high dependency unit (HDU) located within the main theatre complex and patients with critical conditions requiring intensive care are admitted there from various units including the maternity unit.

The eligibility criteria for the study included women with MNM events based on WHO criteria and maternal deaths according to WHO definition among all women with complications during pregnancy, childbirth and within 42 days of termination of pregnancy. ${ }^{7,8,11}$ Women who developed complications after 42 days of termination of pregnancy were excluded from the study.

Ethical approval for the study was obtained from Ethics and Research Committee of Ekiti State University Teaching Hospital, Ado-Ekiti.

\section{Definition of terms}

Maternal near miss events were defined as acute obstetric complications that immediately threaten a woman's survival but do not result in her death because of hospital care she receives during pregnancy, labour or within 6 weeks after termination of pregnancy.

Potential life threatening obstetric conditions (PLTC) referred to maternal complications severe enough to result in near-miss morbidity and maternal death.

Maternal death was defined according to the tenth revision of International Classification of Diseases (ICD10) by the World Health Organization. ${ }^{10}$

Severe maternal outcome was defined as maternal near miss and maternal death.

Data were extracted from the case notes by trained House Officers and Specialist Registrars using a data collection format. This was reviewed at intervals by the principal investigator to check for completeness and consistency of the collected data. The data collection format has two sections. The first section obtained information on the sociodemographic characteristics of the women such as age, parity, marital status, tribe, religion, educational level, occupation, spouse's educational level and occupation and referral status while the second section extracted information about the obstetric history such as present mode of delivery, gestational age at presentation, fetal outcome (birth weight, Apgar scores at birth) and maternal outcome; as well as process indicators regarding 
prevention and treatment of the main causes of MNM and death giving magnesium sulfate for treatment of eclampsia, oxytocin for prevention and treatment of postpartum hemorrhage, and antibiotics for prophylaxis (during cesarean section) and treatment of sepsis.

\section{Statistical analysis}

The data collected was entered into and analysed using Statistical Package for Social Sciences (SPSS, IL) version 22. Continuous data was analysed using mean and standard deviation while categorical data were presented as frequency and percentages. Test of significance was done for continuous data using Student t test while Chi square test or Fischer's exact test was used for categorical data. Logistic regression was done for determinant of severe maternal outcome using Odd ratio and $95 \%$ Confidence interval. Statistical level of significance was set at a $P$ value $<0.05$.

\section{RESULTS}

There were 1897 deliveries, 89 women presented with spontaneous miscarriages and 47 women had ruptured ectopic pregnancy during the study period.

Out of the 1897 deliveries, 1855 were singletons and 42 were twin deliveries. There were 151 women with PLTC and 37 women had severe maternal outcomes; 31 maternal near misses and 6 maternal deaths.

Table 1: Sociodemographic characteristics of the women with maternal near miss experiences.

\begin{tabular}{|c|c|c|c|c|c|}
\hline Variables & $\begin{array}{l}\text { No maternal } \\
\text { complications } \\
\mathbf{n}=\mathbf{1 8 4 2}\end{array}$ & $\begin{array}{l}\text { Potential life- } \\
\text { threatening conditions } \\
\text { (PLTC) } n=151\end{array}$ & $\begin{array}{l}\text { Maternal near } \\
\text { miss (MNM) } \\
n=33\end{array}$ & $\begin{array}{l}\text { Maternal } \\
\text { death (MD) } \\
\mathbf{n}=7\end{array}$ & $\begin{array}{l}\text { p } \\
\text { value }\end{array}$ \\
\hline Age (year) & $30.80 \pm 4.38$ & $28.15 \pm 6.01$ & $26.59 \pm 7.04$ & $29.35 \pm 5.34$ & 0.358 \\
\hline Parity & $1.73 \pm 0.96$ & $1.12 \pm 0.85$ & $1.02 \pm 0.89$ & $1.09 \pm 0.92$ & 0.078 \\
\hline Gestational age (weeks) & $39.19 \pm 1.65$ & $38.01 \pm 1.25$ & $29.63 \pm 1.23$ & $38.17 \pm 1.34$ & 0.623 \\
\hline \multicolumn{6}{|l|}{ Age (years) } \\
\hline$\leq 19$ & $181(9.8)$ & $14(9.3)$ & $3(9.1)$ & $2(28.6)$ & $0.048 *$ \\
\hline $20-35$ & $1321(71.7)$ & $105(69.5)$ & $21(63.6)$ & $1(14.3)$ & \\
\hline$>35$ & $340(18.5)$ & $32(21.2)$ & $9(27.3)$ & $4(57.1)$ & \\
\hline \multicolumn{6}{|l|}{ Marital status } \\
\hline Married & $1715(93.1)$ & $70(46.4)$ & $15(45.5)$ & $3(42.9)$ & 0.065 \\
\hline Single (not married) & $127(6.9)$ & $81(53.6)$ & $18(54.5)$ & $4(57.1)$ & \\
\hline \multicolumn{6}{|l|}{ Education of women } \\
\hline Primary & $339(18.4)$ & $73(48.4)$ & $17(51.5)$ & $4(57.2)$ & $0.034 *$ \\
\hline Secondary & $649(35.2)$ & $38(25.2)$ & $9(27.3)$ & $1(14.3)$ & \\
\hline Tertiary & $854(46.4)$ & $40(26.4)$ & $7(21.2)$ & $2(28.5)$ & \\
\hline \multicolumn{6}{|l|}{ Occupation of women } \\
\hline Unemployed & $319(17.3)$ & $50(33.1)$ & $14(42.4)$ & $3(42.8)$ & 0.423 \\
\hline Self employed & $578(31.4)$ & $44(29.1)$ & $8(24.2)$ & $2(28.6)$ & \\
\hline Privately employed & $538(29.2)$ & $32(21.2)$ & $7(21.2)$ & $1(14.3)$ & \\
\hline Civil servants & $407(22.1)$ & $25(16.6)$ & $4(12.1)$ & $1(14.3)$ & \\
\hline \multicolumn{6}{|l|}{ Occupation of husband } \\
\hline Unemployed & $247(13.4)$ & $47(31.4)$ & $14(42.4)$ & $3(42.8)$ & $0.035^{*}$ \\
\hline Self employed & $378(20.5)$ & $44(29.1)$ & $9(27.3)$ & $2(28.6)$ & \\
\hline Privately employed & $416(22.6)$ & $32(21.2)$ & $6(18.2)$ & $1(14.3)$ & \\
\hline Civil servants & $801(4.35)$ & $28(18.6)$ & $4(12.1)$ & $1(14.3)$ & \\
\hline \multicolumn{6}{|l|}{ Place of residence } \\
\hline Urban & $1334(72.4)$ & $59(39.1)$ & $13(39.4)$ & $2(28.6)$ & $0.012 *$ \\
\hline Rural & $508(27.6)$ & $92(60.9)$ & $20(60.6)$ & $5(71.4)$ & \\
\hline \multicolumn{6}{|l|}{ Booking status } \\
\hline Unbooked & $530(28.8)$ & $81(53.6)$ & $21(63.6)$ & $5(71.4)$ & \\
\hline Booked & $1312(71.2)$ & $70(46.4)$ & $12(36.4)$ & $2(28.6)$ & $0.047 *$ \\
\hline
\end{tabular}

There was no statistical significance difference in the mean age, parity and gestational age at delivery among the women who had no complications, women with potential life threatening conditions and those with severe maternal outcomes. Other socio-demographic variables are as shown in Table 1. 
Table 2: Causes of maternal near miss and maternal death.

\begin{tabular}{|c|c|c|c|c|c|}
\hline Underlying causes & $\begin{array}{l}\text { Women with } \\
\text { PLTC } n=151 \\
(\%)\end{array}$ & $\begin{array}{l}\text { Women with } \\
\text { MNM } \\
\mathbf{n}=\mathbf{3 3}(\%)\end{array}$ & $\begin{array}{l}\text { Maternal } \\
\text { death } \\
\mathrm{n}=7(\%)\end{array}$ & $\begin{array}{l}\text { MNMR/1000 } \\
\text { live births }\end{array}$ & $\begin{array}{l}\text { Mortality } \\
\text { index }\end{array}$ \\
\hline Haemorrhage & $65(43.0)$ & $13(39.4)$ & $2(28.6)$ & 6.8 & 13.3 \\
\hline Abortion & $14(9.3)$ & $1(3.0)$ & $0(0)$ & 0.5 & \\
\hline Ectopic pregnancy & $12(7.9)$ & $2(6.1)$ & $0(0)$ & 1.1 & \\
\hline Placenta abruption & $9(6.0)$ & $2(6.1)$ & $0(0)$ & 1.1 & \\
\hline Placenta praevia & $7(4.6)$ & $1(3.0)$ & $0(0)$ & 0.5 & \\
\hline Postpartum haemorrhage & $23(15.2)$ & $7(21.2)$ & $2(28.6)$ & 3.7 & \\
\hline Hypertensive disorders & $41(27.2)$ & $9(27.3)$ & $1(14.3)$ & 4.7 & 10.0 \\
\hline Severe preeclampsia & $18(11.9)$ & $2(6.1)$ & $0(0)$ & 1 & \\
\hline Eclampsia & $23(15.3)$ & $7(21.2)$ & $1(14.3)$ & 3.7 & \\
\hline Dystocia & $24(15.9)$ & $6(18.2)$ & $3(42.8)$ & 3.2 & 33.3 \\
\hline Prolonged obstructed labour & $17(11.3)$ & $2(6.1)$ & $0(0)$ & 1.1 & \\
\hline Uterine rupture & $7(4.6)$ & $4(12.1)$ & $3(42.8)$ & 2.1 & \\
\hline Infections & $13(8.6)$ & $3(9.0)$ & $1(14.3)$ & 1.6 & 25.0 \\
\hline Anaemia & $8(5.3)$ & $2(6.1)$ & $0(0)$ & 1.1 & \\
\hline
\end{tabular}

Table 2 shows that hemorrhage was the commonest cause of MNM accounting for 13 (39.4\%) followed by hypertensive disorders. Uterine rupture was the leading cause of maternal mortality accounting for 3 (42.8\%) cases and PPH accounted for $2(28.6 \%)$ cases. Uterine rupture had the highest mortality index (MI) of $33.3 \%$ closely followed by infections with a MI of $25 \%$.

Table 3: Frequency of maternal near miss and maternal death by organ dysfunction.

\begin{tabular}{|lllll|}
\hline Organ dysfunction & Maternal near miss* & Maternal death* & $\begin{array}{l}\text { Maternal near miss } \\
\text { ratio }\end{array}$ & $\begin{array}{l}\text { Mortality } \\
\text { index }\end{array}$ \\
\hline Cardiovascular & $18(58.1)$ & $3(50.0)$ & $6: 1$ & 14.3 \\
\hline Renal & $10(32.2)$ & $1(16.6)$ & $10: 1$ & 9.1 \\
\hline Respiratory & $6(19.4)$ & 0 & 0 & - \\
\hline Hepatic & $4(12.9)$ & $1(16.6)$ & $4: 1$ & 20.0 \\
\hline Neurologic & $11(35.5)$ & $2(33.3)$ & $5.5: 1$ & 15.4 \\
\hline Hematologic & $7(22.6)$ & $1(16.6)$ & $7: 1$ & 12.5 \\
\hline Dystocia/Hysterectomy & $3(9.7)$ & $2(33.3)$ & $1.5: 1$ & 40.0 \\
\hline
\end{tabular}

*some women had more than one organ dysfunction

Table 4: Mode of pregnancy termination and neonatal outcome.

\begin{tabular}{|c|c|c|c|c|}
\hline Variables & $\begin{array}{l}\text { No maternal } \\
\text { complications } \\
\mathbf{n}=\mathbf{1 8 4 2}(\%)\end{array}$ & $\begin{array}{l}\text { Women with } \\
\text { PLTC } \\
\mathrm{n}=\mathbf{1 5 1}(\%)\end{array}$ & $\begin{array}{l}\text { Women with } \\
\text { MNM } \\
\mathbf{n}=\mathbf{3 3}(\%)\end{array}$ & $\begin{array}{l}\text { Maternal } \\
\text { death } \\
\mathrm{n}=7(\%)\end{array}$ \\
\hline \multicolumn{5}{|l|}{ Mode of pregnancy termination } \\
\hline Vaginal delivery & $1172(63.6)$ & $64(42.4)$ & $8(24.2)$ & $1(14.3)$ \\
\hline Caesarean delivery & $566(30.7)$ & $59(39.1)$ & $14(42.4)$ & $2(28.6)$ \\
\hline Vacuum aspiration & $73(4.0)$ & $14(9.3)$ & $2(6.1)$ & $1(14.3)$ \\
\hline Laparotomy for rupture uterus/PPH & $0(0)$ & $3(1.3)$ & $5(15.1)$ & $3(42.8)$ \\
\hline Laparotomy for ectopic & $31(1.7)$ & $12(7.9)$ & $4(12.1)$ & $0(0)$ \\
\hline \multicolumn{5}{|l|}{ Neonatal outcome $(n=1939)$} \\
\hline Live births at delivery & $1729(98.4)$ & $135(97.1)$ & $31(91.2)$ & $6(75.0)$ \\
\hline Still births & $29(1.6)$ & $4(2.9)$ & $3(8.8)$ & $2(25.0)$ \\
\hline Neonatal deaths* & $19(1.1)^{\dagger}$ & $1(0.7)^{\dagger}$ & $1(2.9)^{\dagger}$ & $0(0)$ \\
\hline Total deaths $(\text { Still birth+NND) })^{\mathrm{x}}$ & $48(2.7)$ & $5(3.6)$ & $4(11.8)$ & $2(25.0)$ \\
\hline
\end{tabular}

*Part of the initial live births at delivery; ${ }^{\dagger}$ Percentage of the live births alone in each group; ${ }^{x}$ Percentage of total births in each group. 
Cardiovascular dysfunction $(58.1 \%)$ was the most common organ dysfunction among the women with MNM followed by neurologic dysfunction (35.5\%). The MI was highest among women who had dystocia and hysterectomy accounting for $40 \%$ while the maternal near miss/ mortality ratio was highest in women with renal dysfunction (10:1) and followed by hematologic dysfunction $(7: 1)$ and multiple organ dysfunctions $(7: 1)$ as seen in Table 3 .

Caesarean section (CS) was the commonest mode of delivery in women with PLTC (39.1\%) and MNM $(42.4 \%)$ while maternal death was highest in women who had laparotomy for uterine rupture $(42.8 \%)$. Neonatal outcomes (perinatal deaths) were worst among women with maternal deaths in Table 4.

Table 5: Severe maternal outcome, near miss indicator and facility related indicator.

\begin{tabular}{|c|c|}
\hline Maternal outcomes and indicators ${ }^{a}$ & Value \\
\hline Severe maternal outcomes (SMO) & 40 \\
\hline Maternal near miss (MNM) & 33 \\
\hline Maternal death & 7 \\
\hline \multicolumn{2}{|l|}{ Overall near miss indicator } \\
\hline 'SMO ratio/1000 live births & $\begin{array}{l}21.1 \\
(18.2-25.1)\end{array}$ \\
\hline MNM incidence ratio/1000 live births & $\begin{array}{l}17.4 \\
(15.3-20.2)\end{array}$ \\
\hline${ }^{\mathrm{d}} \mathrm{MNM}$ mortality ratio & $4.7: 1$ \\
\hline${ }^{\mathrm{e}}$ Mortality index & $\begin{array}{l}17.5 \\
(15.3-23.4)\end{array}$ \\
\hline \multicolumn{2}{|l|}{ Hospital access indicator ${ }^{b}$} \\
\hline $\begin{array}{l}\text { SMO cases with organ dysfunction or } \\
\text { maternal death within } 12 \mathrm{~h} \text { of hospital } \\
\text { stay (SMO12) }\end{array}$ & 27 \\
\hline $\begin{array}{l}\text { Percentage of SMO12 cases among all } \\
\text { SMO cases }\end{array}$ & $\begin{array}{l}67.5 \\
(64.7-70.1)\end{array}$ \\
\hline SMO12 mortality index & $\begin{array}{l}7.5 \\
(3.1-14.3)\end{array}$ \\
\hline \multicolumn{2}{|l|}{ Intensive care use } \\
\hline $\begin{array}{l}\text { Percentage of intensive care unit (ICU) } \\
\text { admission }\end{array}$ & $1.7(1.3-1.9)$ \\
\hline $\begin{array}{l}\text { Percentage of ICU admission among } \\
\text { women with SMO }\end{array}$ & $\begin{array}{l}30.3 \\
(20.2-43.3)\end{array}$ \\
\hline $\begin{array}{l}\text { Percentage of SMO among women } \\
\text { admitted to ICU }\end{array}$ & $\begin{array}{l}75.9 \\
(45.1-94.3)\end{array}$ \\
\hline $\begin{array}{l}\text { Percentage of maternal deaths occurred } \\
\text { without ICU admission }\end{array}$ & $\begin{array}{l}51.3 \\
(20.4-87.4)\end{array}$ \\
\hline \multicolumn{2}{|c|}{$\begin{array}{l}\text { 'Based on data from all women }(\mathrm{n}=2033) \text {; }{ }^{\mathrm{b}} \mathrm{The} \text { denominator } \\
\text { for these } 2 \text { indicators is 'live births' }(\mathrm{n}=1901) \text {; 'Severe } \\
\text { Maternal Outcome Ratio (SMOR): The number of women with } \\
\text { life threatening conditions (MNM+ MD) per } 1000 \text { live births } \\
\text { (LB).; 'Maternal near miss mortality ratio (MNMR): The } \\
\text { number of maternal near miss cases per } 1000 \text { live births } \\
\text { (MNMR = MNM/LB); 'Mortality index (MI): The number of } \\
\text { maternal deaths divided by the number of women with life- } \\
\text { threatening conditions expressed as a percentage (MI = MD/ } \\
\text { MNM+MD). }\end{array}$} \\
\hline
\end{tabular}

The SMO ratio was 21.1 per 1000 live birth and the MNM ratio was 17.4 per 1000 live birth. The maternal mortality ratio (MMR) was 932 per 100000 live birth, the mortality index $(\mathrm{MI}=$ maternal deaths $/ \mathrm{MNM}+$ maternal deaths) was $17.5 \%$, the maternal near/miss mortality ratio was 4.7:1. Among the 151 women with potential life threatening conditions, 53 (35.1\%) had blood transfusions and laparotomies were done in $13.9 \%$. The HDU admission rate was $1.6 \%$ (33/2033) among all women, whereas ICU admission rate among women with SMO was $17.5 \%(7 / 40)$ as in Table 5.

Table 6: Socio-demographic characteristics associated with near miss cases on logistic regression.

\begin{tabular}{|c|c|c|}
\hline Variables & $\begin{array}{l}\text { Adjusted Odd ratio } \\
\text { (95\% Confidence } \\
\text { interval }\end{array}$ & $\begin{array}{l}\text { p } \\
\text { value }\end{array}$ \\
\hline \multicolumn{3}{|c|}{ Age of women (years) } \\
\hline$<35$ & 1 & \\
\hline$\geq 35$ & $1.95(1.50-2.30)$ & $0.001 *$ \\
\hline \multicolumn{3}{|c|}{ Education of women } \\
\hline Primary and below & $1.58(1.20-2.30)$ & $0.012 *$ \\
\hline Post-primary & 1 & \\
\hline \multicolumn{3}{|c|}{ Occupation of husband } \\
\hline Unemployed & $0.53(0.32-0.64)$ & 0.058 \\
\hline Employed & 1 & \\
\hline \multicolumn{3}{|l|}{ Place of residence } \\
\hline Rural & $1.48(1.08-1.98)$ & $0.039 *$ \\
\hline Urban & 1 & \\
\hline \multicolumn{3}{|l|}{ Booking status } \\
\hline Unbooked & $1.73(1.53-1.88)$ & $0.025^{*}$ \\
\hline Booked & 1 & \\
\hline
\end{tabular}

\section{DISCUSSION}

The incidence of MNM in this study was 17.4/ 1000 live births and is comparable to reports from urban Ghana and Northern Tanzania but higher than findings from the developed countries. ${ }^{3,12-14}$ This high rate might be partly due to differences in definition and identification of cases which are major limitations in comparison of near-miss data across institutions. ${ }^{3}$ Also, it may also be as a result of the fact that the study centre is a referral hospital that receives complicated cases from the primary and secondary hospitals within the state and the surrounding states. The mortality index recorded in this study was $17.5 \%$ and is comparable to findings from studies done in other low resource settings in Africa but higher than findings in developed countries. ${ }^{4,15-18}$ This might due to the fact a lot of women with critical conditions in low resource setting still die from these complications as was expressed in some previous studies. ${ }^{18,19}$

Hemorrhage and hypertension were the major causes of potential life threatening conditions in this study with hemorrhage still the leading cause. This was similarly reported in some studies done in Africa ${ }^{13,15,21}$ but differs from similar studies carried out in Brazil and India where 
hypertensive disorders were mostly associated with near miss. ${ }^{13,15,21-23}$ However, postpartum hemorrhage and uterine rupture were the leading causes of maternal deaths in this study. This might still be a reflection of poor management of labour cases in the peripheral health centre with majority of them being referred in critical conditions. This implies that efforts need to be focused on improving the protocols and resources for combating postpartum haemorrhage and uterine rupture at the tertiary centres, while improving the management of labour at the peripheral centre by ensuring women in rural areas have access to antenatal care in pregnancy and skilled birth attendants at delivery. The use of Magnesium sulphate - which has been shown to reduce eclampsia related risk of maternal mortality in our centre in the treatment and prevention of eclampsia resulted in the reduction of contribution of eclampsia to maternal morbidity and mortality. ${ }^{24}$ This is unlike study done in Sagamu by Oladapo et al where eclampsia was the leading cause of maternal death and it was due to nonadoption of the evidence based protocol on the use of Magnesium Sulphate in the management of eclampsia. ${ }^{10}$

Women with severe maternal outcomes were mostly unbooked that were transferred from the peripheral hospitals, private hospitals and faith based homes. This might be due to delay in seeking and reaching appropriate care because of lack of proper referral system and early detection of potentially life threatening complications in these women outside the tertiary health centre. This also accounted for the higher mortality index among them when compared to women that were managed from within the hospital. This was similarly reported in a study by Adisasmita et al but in contrast to findings of Jabir et al who reported in their study that there was no difference in the mortality index among them. ${ }^{19,25}$

The maternal death-near miss ratio is a useful indicator of the quality of care received by near-miss cases irrespective of their primary source of antenatal or labour care. ${ }^{10} \mathrm{~A}$ maternal death to near-miss ratio of approximately 1:5 recorded in this study shows that for every 5 women who survived life-threatening complications, one maternal death occurred. The same ratio was similarly reported in Sagamu, Nigeria and is poorer than 1:11-22 reported from similar centres in Niger, ${ }^{26}$ Cote d'Ivoire and Benin. ${ }^{10,26,27}$ It is also a far cry from the 1: 17-223 reported in Europe. ${ }^{28}$ There is need to improve the quality of obstetric care services offered in this centre so as to improve the chances of survival of the near miss cases.

The caesarean section (CS) rate in this study was $33.7 \%$ which is higher than the recommended WHO CS rate but is comparable to rate reported by Kalisa et al in Rwanda and lower than that of Litorp et al in Tanzania. ${ }^{16,18,29}$ This high rate might be because this was the most common mode of delivery in women with PLTC and maternal near miss and that instrumental delivery is becoming a dying art. The mortality associated with caesarean section in this study was twice that of vaginal delivery and this further confirmed the previous findings of association between MNM and deaths attributed to CS complications due to the increasing CS rates especially in developing countries including Nigeria. ${ }^{19}$ The estimated risk of death of 3.3/1000 due to CS complications was comparable to that reported in Tanzania by Litorp et al but higher than the United States reported figure by Clark et al and this is a reflection of the potential danger associated with CS in developing countries. ${ }^{18,30}$

About $50 \%$ of maternal deaths recorded in this study occurred in women who had hysterectomy as a form of treatment for PPH and uterine rupture. Prolonged obstructed labour which was the main factor leading to uterine rupture occurred mostly in the referred cases and is a reflection of the level of care at the referring centre. A Malawian study recommended training of healthcare workers in order to reduce delay in diagnosing and treatment of obstructed labour as well as implementation of local guidelines for augmentation of labour. ${ }^{31}$ This increased supervision would lead to improved documentation and labour management and eventual reduction in cases of obstructed labour and uterine rupture. $^{13,21}$

All the women who had vaginal and caesarean deliveries were given oxytocic drugs (oxytocin or ergometrine) as recommended by WHO for the prevention and treatment of postpartum hemorrhage. ${ }^{32}$ In addition to this, women who had risk factors for PPH and few who developed PPH had sublingual misoprostol since misoprostol has been recommended by WHO in its treatment and prevention. ${ }^{32}$ So, the use of uterotonic agents was quite high in our centre which was in agreement with findings in Rwanda ${ }^{16}$ but unlike the study in Tanzania where the use of oxytocics was reportedly low. ${ }^{13}$ This might explain why the contribution of $\mathrm{PPH}$ to maternal death in our centre was low.

Women with PLTC and MNM might require levels of care that differ from one to another, ranging from basic obstetric care to comprehensive obstetric care including surgery and intensive care as the case may be. Women with organ dysfunction are better managed in the intensive care unit (ICU). ${ }^{17,33}$ There was low ICU admission observed in this study and this reflected the shortage of ICU beds such that women experiencing organ dysfunctions did not have access to ICU care before their eventual death. This was similarly recorded in previous studies in developing countries. ${ }^{17,25,26}$ They opined that the provision of adequate ICU, trained personnel, equipment and management protocols would result in a better outcome among women with lifethreatening conditions. ${ }^{17,32}$

Advancing maternal age was found to be a determinant of MNM in this study where more than half of the maternal death occurred in the older age group. This was similarly reported in previous studies. ${ }^{26,34}$ This might be due to the 
fact a lot of medical conditions like hypertension and diabetes mellitus that may complicate pregnancy are commoner in the older age group. Higher parity (grandmultiparity) with its attendant complications may also be associated with advancing maternal age. However, studies by Adisasmita et al and Naderi et al reported that primiparity was associated with increased frequency of MNM cases. ${ }^{26,34}$

The occurrence of MNM was commonly found among women with low education. This is because lack of education will limit access to information about their health and female education has been shown to be associated with better knowledge of their health, improved decision-making capabilities and increased utilisation of maternal health services. ${ }^{34}$ In contrast, WHO global survey revealed that the near miss ratio was significantly associated with higher educational levels. This finding was attributed to the fact that women with higher educational levels might want to undergo caesarean section, which increases the probability of near miss events. ${ }^{34}$ This is very unlikely in our setting where a lot of women irrespective of their educational level have strong aversion for $\mathrm{CS} .{ }^{36}$

Women who resided in rural areas had more SMO compared to the women who resided in the urban areas and attended antenatal clinic sessions. This was consistent with findings from previous studies conducted in Ethiopia and Iraq. ${ }^{17,37}$ This could be due to the fact that women in the urban areas have more access to information and better health care services unlike the rural women that might be influenced by cultural belief and practices. ${ }^{37}$ Also, women who did not have their antenatal care at the centre and were referred had severe outcomes in this review. This is because many of these women were critically ill or unstable at admission due to delayed referrals or late arrival at the referral centre. The late arrival at the referral centre might be due to the distance between their place of residence and this referral centre and lack of transportation. Lack of money to access good health care could also be contributory to the late arrival at the referral centre since spousal unemployment was significantly associated with MNM in this review. This is line with the three phases of delay of maternal mortality, specifically delay in reaching health facility and this was similarly reported in other studies. $^{37,38}$

The strength of this study lies in the fact WHO criteria used helped us to identify women with organ dysfunctions, which is more reliable in reflecting PLTC than using a diagnosis-based inclusion. This first maternal near miss review will serve as baseline findings with which subsequent reviews can be compared as a monitor of the improvement in the quality of obstetric care. The limitations of this review included the fact that no follow up was done for the women after their discharge from hospital and some women may have died at home or at another institution within 42 days. This might have underestimated the number of maternal deaths. Also, autopsies were not performed such that the underlying cause of death was based only on information obtained from their case record.

In conclusion, the overall maternal near miss death ratio shows a suboptimal level of care for women with PLTC. This was also reflected by the low HDU admissions due to absence of space for those who were critically ill. This study also revealed that reducing maternal mortality will involve a good referral system, proper management of the near miss cases and access to reliable contraceptive methods like implants, intrauterine devices and sterilization. There should be provision of evidence-based protocols and HDU within the obstetric unit for the management of the critical conditions. Staff in the obstetric unit should undergo regular training in emergency obstetric services and emergency drills should be conducted too. Since this is the first maternal near miss review in this centre, it would be suggested that it should be done at intervals and it would help to evaluate and monitor the quality of obstetric care in this centre.

\section{ACKNOWLEDGMENTS}

The authors acknowledged the Specialist registrars, the House Officers and staff of the Medical Record Department that assisted in the collation of the data.

Funding: No funding sources

Conflict of interest: None declared

Ethical approval: The study was approved by the Institutional Ethics Committee

\section{REFERENCES}

1. Pattinson RC, Buchmann E, Mantel G, Schoon M, Rees H. Can enquiries into severe acute maternal morbidity act as a surrogate for maternal death enquiries? Br J Obstet Gynecol. 2003;110:889-93.

2. Khan KS, Wojdyla D, Say L, Gülmezoglu AM, Van Look PF. WHO analysis of causes of maternal death: a systematic review. Lancet. 2006;367:1066-74.

3. Say L, Pattinson RC, Gulmezoglu AM. WHO systematic review of maternal morbidity and mortality: the prevalence of severe acute maternal morbidity (near miss). Reprod Health. 2004;1:3.

4. Tunçalp Ö, Hindin MJ, Souza JP, Chou D, Say L. The prevalence of maternal near miss: a systematic review. BJOG. 2012;119:653-61.

5. Waterstone M, Bewley S, Wolfe C. Incidence and predictors of severe obstetric morbidity: case-control study. BMJ. 2001;322:1089-93.

6. Mantel GD, Buchmann E, Rees H, Pattinson RC. Severe acute maternal morbidity: a pilot study of a definition for a near-miss. Br J Obstet Gynecol. 1998;105:985-90.

7. WHO, World Health Organization. Evaluating the Quality of Care for Severe Pregnancy Complications: The WHO Near-Miss Approach for Maternal Health. 
Geneva: WHO 2001. Available at http://apps.who.int/iris/bitstream/10665/44692/2/978 9241502221 eng.pdf accessed on March 10, 2017

8. Say L, Souza JP, Pattinson RC. Maternal near miss towards a standard tool for monitoring quality of maternal health care. Best Pract Res Clin Obstet Gynecol. 2009;23:287-96.

9. Pattinson R, Say L, Souza JP, Van Den Broek N, Rooney C. WHO Working Group on Maternal Mortality and Morbidity Classifications: WHO maternal death and near-miss classifications. Bull World Health Org. 2009;87:734.

10. Oladapo OT, Sule-Odu AO, Olatunji AO, Daniel OJ. "Near-miss" obstetric events and maternal deaths in Sagamu, Nigeria: a retrospective study. Reprod Health. 2005;2:9.

11. World Health Organization. ICD-10: International statistical classification of diseases and health-related problems. In Tenth Revision Volume 2. Geneva: WHO 1993 Available at http://www.who.int/classifications/icd/ICD10volume 2_en_2010.pdf accessed on March 10, 2017

12. Tunçalp O, Hindin MJ, Adu-Bonsaffoh K, Adanu RM. Assessment of maternal near-miss and quality of care in a hospital-based study in Accra, Ghana. Int J Gynecol Obstet. 2013;123:58-63.

13. Nelissen EJT, Mduma E, Ersdal HL, Evjen-Olsen B, van Roosmalen JJM, Stekelenburg J. Maternal near miss and mortality in a rural referral hospital in northern Tanzania: A cross-sectional study. BMC Pregnancy Childbirth. 2013;13:141.

14. Chhabra P. Maternal near miss: an indicator for maternal health and maternal care. Ind J Comm Med. 2014;39:132-7.

15. Rulisa S, Umuziranenge I, Small M, van Roosmalen J. Maternal near miss and mortality in a tertiary care hospital in Rwanda. BMC Pregnancy Childbirth. 2015;15:203.

16. Kalisa R, Rulisa S, van den Akker T, van Roosmalen J. Maternal Near Miss and quality of care in a rural Rwandan hospital. BMC Pregnancy Childbirth. 2016;16:324.

17. Lotufo FA, Parpinelli MA, Haddad SM, Surita FG, Cecatti JG. Applying the new concept of maternal near-miss in an intensive care unit. Clinics. 2012;67:225-30.

18. Litorp H, Kidanto LH, Rööst M, Abeid M, Nyström L, Essén B. Maternal near-miss and death and their association with caesarean section complications: a cross-sectional study at a university hospital and a regional hospital in Tanzania. BMC Pregnancy Childbirth. 2014;14:244.

19. Ali AA, Khojali A, Okud A, Adam GK, Adam I. Maternal near-miss in a rural hospital in Sudan. BMC Pregnancy Childbirth. 2011;11:48.

20. Jabir M, Abdul-Salam I, Suheil DM, Al-Hill W, Abul-Hassan S, Al-Zuheiri A et al. Maternal near miss and quality of maternal health care in Baghdad, Iraq. BMC Pregnancy Childbirth. 2013;13:11.
21. van den Akker T, Beltman J, Leyten J, Mwagomba B, Meguid T, Stekelenburg $\mathrm{J}$ et al. The WHO maternal near miss approach: consequences at Malawian District level. PLoS One 2013;8:e54805.

22. Pattinson RC, Hall M (2003). Near misses: a useful adjunct to maternal death enquiries. Br Med Bull. 2003;67:231-43.

23. Jyoti B, Garima S. Clinical and etiological study of maternal near-miss at a tertiary referral hospital of Central India. Ind J Obstet Gynecol Res. 2016;3:2831.

24. Duley L, Gülmezoglu AM, Henderson-Smart DJ. Magnesium sulphate and other anticonvulsants for women with preeclampsia. The Cochrane Database Syst Rev. Art. 2003 No.: CD000025.

25. Adisasmita A, Deviany PE, Nandiaty F, Stanton C, Ronsmans C. Obstetric near miss and deaths in public and private hospitals in Indonesia. BMC Pregnancy Childbirth. 2008;8:10.

26. Prual A, Huguet D, Gabin O, Rabe G. Severe obstetric morbidity of the third trimester, delivery and early puerperium in Niamey (Niger). Afr $\mathbf{J}$ Reprod Health. 1998;2:10-9.

27. Filippi V, Ronsmans C, Gohou V, Goufodji S, Lardi M, Sahel A et al. Maternity wards or emergency obstetric rooms? Incidence of near-miss events in African hospitals. Acta Obstet Gynecol Scand. 2005;84:11-6.

28. Say L, Pattinson RC, Gülmezoglu AM. WHO systematic review of maternal morbidity and mortality: the prevalence of severe acute maternal morbidity (near miss). Reprod Health. 2004;1:3.

29. World Health Organization. WHO statement on caesarean section rates. WHO Geneva 2015. Available at http//:apps.who.int/WHO.RHR.5.02 eng.pdf accessed on August 2, 2017.

30. Clark SL, Belfort MA, Dildy GA, Herbst MA, Meyers JA, Hankins GD. Maternal death in the $21^{\text {st }}$ century: causes, prevention, and relationship to cesarean delivery. Am J Obstet Gynecol. 2008;199:3.

31. van den Akker $T$, Mwagomba B, Irlam J, Van Roosmalen J (2009). Using audits to reduce the incidence of uterine rupture in a Malawian district hospital. Int J Gynaecol Obstet. 2009;107:289-94.

32. World Health Organization. WHO recommendations for the prevention of postpartum hemorrhage. WHO 2007 Available at http://apps.who.int/iris/bitstream/10665/75411/1/978 9241548502eng.pdf accessed on March 12, 2012.

33. Zeeman GG. Obstetric critical care: a blueprint for improved outcomes. Crit Care Med. 2006;34:S208S214.

34. Naderi T, Foroodnia S, Omidi S, Samadani F, Nakhaee N. Incidence and correlates of maternal near miss in Southeast Iran. Int J Reprod Med. 2015;Article ID 914713:5.

35. Mpembeni RNM, Killewo JZ, Leshabari MT, Massawe SN, Jahn A, Mushi D et al. Use pattern of maternal health services and determinants of skilled care during delivery in southern Tanzania: 
implications for achievement of MDG-5 targets. BMC Pregnancy Childbirth. 2007;7:29.

36. Sunday-Adeoye I, Kalu CA. Pregnant Nigerian women's view of caesarean section. Niger J Clin Pract. 2011;14:276-9.

37. Gedefaw M, Gebrehana H, Gizachew A, Taddess F. Assessment of maternal near miss at Debre Markos referral hospital, Northwest Ethiopia: Five Years' Experience. Open J Epidemiol. 2014;4:199-207.
38. Abdella A. Maternal mortality trend in Ethiopia. Eth J Health Dev. 2010;24:115-22.

Cite this article as: Aduloju OP, Aduloju T, Ipinnimo OM. Profile of maternal near miss and determinant factors in a Teaching Hospital,

Southwestern Nigeria. Int J Reprod Contracept Obstet Gynecol 2018;7:3450-8. 